\title{
APROVEITAMENTO DE CAPEAMENTO DE MINAS DE MINÉRIO DE FERRO ATRAVÉS DE PROCESSO DE CALCINAÇÃO FLASH PARA PRODUÇÃO DE LIGANTE DE ALTA RESISTÊNCIA*
}

\section{Resumo}

Evandro Moraes da Gama ${ }^{1}$ Abdias Magalhães Gomes ${ }^{2}$ Cláudio Batista Vieira ${ }^{3}$

Os solos de capeamento de minas de minério de ferro, calcário, gnaisse, granito, entre outros, possuem um característica em comum, são solos lateríticos gerados a partir das intempéries e alteração das rochas citadas. Este fato proporciona a formação dos minerais caulinita, goethita, ilita, etc. na composição mineralógica desses estéreis. Em função de suas características químicas e mineralógicas esses estéreis argilosos podem ser utilizados como matéria-prima para produção de ligantes de alta resistência e de múltiplas aplicações. Nesse trabalho é apresentada a tecnologia flash para calcinação de solos de capeamento de minas para produção desses ligantes (PI 0604142-6A). Essa tecnologia permite processamento termoquímico de material pulverulento, ou seja partículas finas, o que não é possível em fornos convencionais de calcinação. No reator flash as partículas de estéreis argilosos são expostas a temperaturas moderadas durante frações de segundo, provocando o fenômeno de desidroxilação dos minerais hidratados contribuindo para a formação de metacaulinita, metagoethita, metailita, etc. Em função das condições cinéticas e termodinâmicas reinantes no processo os constituintes mineralógicos produzidos são amorfos e possuem uma alta superfície de reação, permitindo alcançar valores típicos de área superficial do ligante acima de $90 \mathrm{~m}^{2} / \mathrm{grama}$. Os ligantes produzidos a partir desses estéreis apresentam aplicações em diversas áreas tais como indústria cimenteira, construção civil, pavimentação e metalurgia.

Palavras-chave: Capeamento de minas; Estéreis argilosos; Calcinação flash; Ligantes.

\section{UTILIZATION OF OVERBURDEN FROM IRON ORE MINES IN THE PRODUCTION OF HIGH STRENGTH BINDER THROUGH THE PROCESS OF FLASH CALCINATION}

\section{Abstract}

The contribution of calcinate clay and, specially, the contribution of metakaolin in high-peformance concrete production are considerate, in modern world, a practicable and applicable solution in civil construction. This paper introduces results of a concrete search with clay improvement in a calcination system according to DEMETER's project. It will present data relating to physics and mechanics properties of produced concrete, aimed at durability, quality and metakaolin addition.

Keywords: Flash calcination; Metakaolin; High-performance concrete.

1 Eng. de Minas, Geólogo de Engenharia, Hidrogeólogo, PhD, Prof. Associado do Departamento de Eng. de Minas da Escola de Engenharia, Universidade Federal de Minas Gerais (UFMG), Belo Horizonte, MG, Brasil.

2 Eng. Civil, Dr., Prof. Associado do Departamento de Engenharia de Materiais e Construção da Escola de Engenharia, UFMG, Belo Horizonte, MG, Brasil.

3 Eng. Metalurgista, M.Sc., Dr., Prof. do Departamento de Eng. Metalúrgica e de Materiais da Escola de Minas, Universidade Federal de Ouro Preto (UFOP); Prof. da REDEMAT, Ouro Preto, MG, Brasil.

\footnotetext{
* Contribuição técnica ao 44 Seminário de Redução de Minério de Ferro e Matérias-primas, 15ํ Simpósio Brasileiro de Minério de Ferro e $2^{\circ}$ Simpósio Brasileiro de Aglomeração de Minério de Ferro, 15 a 18 de setembro de 2014, Belo Horizonte, MG, Brasil.
} 


\section{INTRODUÇÃO}

O aumento da durabilidade das estruturas de concreto armado é um tema que têm sido objeto de estudos específicos ao longo dos últimos anos, sobretudo voltadas para as construções que apresentam indícios de deterioração prematura, quer seja por corrosão das armaduras ou através da ação de outros agentes agressivos. A partir da década de 60 foi adotada a técnica do aumento da resistência do concreto com o intuito de reduzir a porosidade e, por consequência, melhorar a durabilidade como subproduto do ganho de resistência. Segundo Mehta [1], a durabilidade em longo prazo de um concreto de alta resistência pode não qualificá-lo, por si só, como concreto de alto desempenho devido ao grande consumo de cimento demandado, existindo a possibilidade de ocorrência de fissuras pelo efeito da retração. $O$ conceito do concreto de alto desempenho surgiu na década de 90 graças ao emprego de adjuvantes superplastificantes e de adições minerais que propiciaram a produção de concretos com baixo fator água/aglomerante e com grande trabalhabilidade. A utilização de pozolanas como adição mineral ao concreto é muito recente. Materiais como escória de alto forno e cinza volante foram os primeiros materiais deste tipo a serem adicionados ao cimento com o objetivo de melhorar as propriedades do cimento e consequentemente do concreto, diminuindo também o custo do produto final. Face ao custo de transporte e à disponibilidade do produto (escória de alto forno e cinza volante), os cimentos compostos representaram, no passado, uma pequena fatia da produção mundial e sobretudo brasileira. Hoje a situação é totalmente inversa, na medida em que a necessidade imposta pelos organismos de proteção ambiental fez com que todas as empresas, potenciais geradores de adições e resíduos, dessem um destino ordenado ao passivo ambiental.

\subsection{O Sistema de Calcinação Rápido (Flash)}

O sistema de calcinação é composto de transportador pneumático onde o material é recuperado por ciclones. A concepção é modular, podendo ser transportado como uma carreta atrelada a um cavalo mecânico, não necessitando de fundação ou montagens especiais. A figura 1 mostra uma vista lateral do sistema. Os componentes são moenga e conversor de alimentação, desagregador e secador, pré-câmara de calor, calcinador, resfriadores com ciclones e silo de estocagem. A instalação é transportada facilmente assim como os acessórios. Nas figuras 1 ((a) e (b)) é apresentado o equipamento calcinador embalado e versátil para ser transportado.

\footnotetext{
* Contribuição técnica ao $44^{\circ}$ Seminário de Redução de Minério de Ferro e Matérias-primas, 15ํ Simpósio Brasileiro de Minério de Ferro e $2^{\circ}$ Simpósio Brasileiro de Aglomeração de Minério de Ferro, 15 a 18 de setembro de 2014, Belo Horizonte, MG, Brasil.
} 
do metacaulim, como um material com propriedades pozolânicas, é atingir uma desidroxilação completa, mas sem, no entanto, queimar integralmente o material. Processos positivos resultam em uma estrutura desordenada e amorfa, altamente pozolânica. A exposição térmica, além do ponto definido, irá resultar na sinterização e na formação de mulita, a qual foi morta pela queima e não tem propriedades reativas [2]. Para a obtenção do metacaulim é necessário que a caulinita passe por um processo chamado calcinação, tal como mostrado na Figura 2.

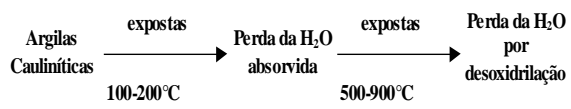

Figura 2. Esquema de calcinação do Metacaulim

Para obter sucesso neste processo é necessário que seja feito um controlo de temperatura do tempo de exposição e da qualidade do material. É importante salientar que para cada utilização da meta caulinita é preciso adequar os controlos térmico e granulométrico [2].

\subsubsection{Cimento Portland}

O cimento utilizado para a confecção do concreto foi o CPV-ARI, cimento contendo $96 \%$ de clínquer e $4 \%$ de gesso, fabricado no Brasil, e nomeado como cimento de alta resistência iniciais (similar ao classe 53,5 fabricado na Europa Comunitária).

\subsubsection{Areia}

A areia utilizada para o ensaio da resistência à compressão do concreto foi uma areia normalizada, quartzosa e seguindo às especificações contidas na norma Brasileira NBR 7214/82 [4].

\subsection{5 Água}

Toda a água utilizada para a confecção e cura do concreto durante a pesquisa foi fornecida pelo sistema de abastecimento público da cidade de Belo Horizonte, sendo considerada uma água de potabilidade garantida. e adequada à produção de concretos.

\subsubsection{Aditivo}

Foi utilizado um adjuvante superplastificante (polifuncional típico de mercado) para a confecção do concreto.

\section{RESULTADOS E DISCUSSÃO}

\subsection{Resistência à Compressão}

Os concretos foram preparados conforme a norma Brasileira NBR-12821/93. Este ensaio teve como objetivo avaliar o comportamento da resistência mecânica do concreto confeccionado com os materiais citados no item anterior nas idades iniciais bem como de sua evolução durante os 28 dias de cura em laboratório. Os provetes utilizados são cilindros de $10 \mathrm{~cm}$ de diâmetro e $20 \mathrm{~cm}$ de altura. Foram produzidos em laboratório três diferentes tipos de concretos, a saber: um concreto de referência sem adição de metacaulim produzido apenas com cimento portland; um concreto com substituição de $20 \%$ do cimento por metacaulim fino (metacaulim passante na peneira $0,075 \mathrm{~mm}$ ) e, finalmente, um concreto com adição substituição de $20 \%$ do

* Contribuição técnica ao $44^{\circ}$ Seminário de Redução de Minério de Ferro e Matérias-primas, 15오 Simpósio Brasileiro de Minério de Ferro e 2ํ Simpósio Brasileiro de Aglomeração de Minério de Ferro, 15 a 18 de setembro de 2014, Belo Horizonte, MG, Brasil. 
cimento por metacaulim grosso (metacaulim retido na peneira $0,075 \mathrm{~mm}$ ). A composição do concreto referência expresso em peso de material seco foi 1: 1,40: $1,04: 1,56$ (cimento, areia, inerte calcário graduação no 0 e inerte calcário graduação no1) com relação água-aglomerante (a/a) igual a 0,49 e adjuvante super-plastificante doseado a $0,50 \%$ do peso de cimento utilizado. Este concreto tem resistência característica típica de um B40. Os resultados obtidos após o ensaio de compressão são apresentados na Tabela 1, e indicaram um ganho na resistência mecânica final do concreto, tanto nas idades iniciais quanto nas idades finais, atuando da substituição do cimento por $20 \%$ de metacaulim. Após a análise dos resultados observa-se que o metacaulim utilizado na substituição de $20 \%$ do cimento no concreto, trouxe um ganho de $9,72 \%$ na resistência à compressão na idade de 3 dias, e um aumento final na sua resistência aos 28 dias em torno 6,59\%.

Tabela 1. Resultados de resistência à compressão do concreto com adição de $20 \%$ de metacaulim fator a/a 0,49 .

\begin{tabular}{|c|c|c|c|}
\hline \multicolumn{4}{|c|}{ Resistência a Compressão (Mpa) } \\
\hline Referência & 3 dias & 7 dias & 28 dias \\
\hline $\begin{array}{c}\text { Material } \\
\text { Fino }\end{array}$ & 39,0 & 42,0 & 45,5 \\
\hline $\begin{array}{c}\text { Material } \\
\text { Grosso }\end{array}$ & 39,0 & 45,0 & 48,5 \\
\hline
\end{tabular}

* valor médio de $6 \mathrm{cp}$ 's

$\mathrm{Na}$ Figura 3, pode-se observar o corpo de prova de concreto com metacaulim fino após seu rompimento.

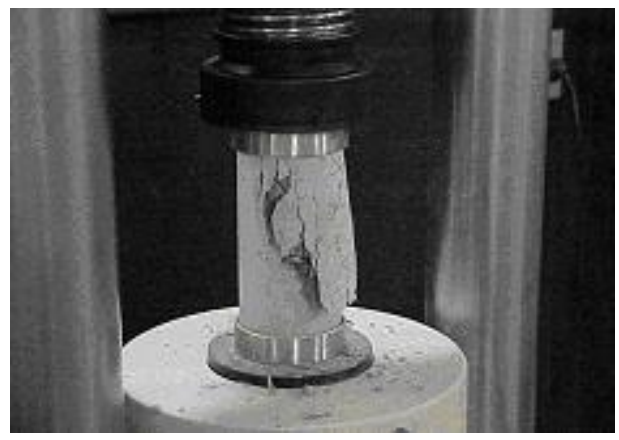

Figura 3. Corpo de prova contendo metacaulim flash

Mantendo a relação a/a constante em 0,49 para as três amostras (referência, material fino e material grosso), observou-se uma redução considerável na consistência e trabalhabilidade do concreto, medida através do "slump test" que indicou $12 \mathrm{~cm}$ no traço de referência e $6 \mathrm{~cm}$ nos traços com adição do metacaulim. Esta perda de trabalhabilidade poderá ser compensada através do aumento da dosagem do aditivo para $0,75 \%$, sem perda de resistência.

\subsection{Durabilidade do Concreto}

Segundo Mehta [1], uma longa vida útil é considerada sinônimo de durabilidade. De acordo com o Comitê 201 do ACl-American Concrete Institutte, durabilidade do concreto produzido com cimento Portland é definida como sua capacidade de resistir

\footnotetext{
* Contribuição técnica ao $44^{\circ}$ Seminário de Redução de Minério de Ferro e Matérias-primas, 15ํ Simpósio Brasileiro de Minério de Ferro e $2^{\circ}$ Simpósio Brasileiro de Aglomeração de Minério de Ferro, 15 a 18 de setembro de 2014, Belo Horizonte, MG, Brasil.
} 
à ação das intempéries, ataques químicos, abrasão ou qualquer outro processo de deterioração. A durabilidade do concreto está, entre outros fatores, relacionado com a estrutura dos poros, principalmente pela capacidade de transportar água e ainda permitir a difusão de íons nocivos. Assim sendo, o metacaulim quando incorporado ao concreto produz um refinamento substancial nos poros, o que, em princípio, aumenta a durabilidade desse concreto [3]. De acordo com Mehta [1], a água é o agente primário tanto da criação quanto da destruição de muitos materiais na natureza e é o fator central para a maioria dos problemas de durabilidade do concreto. Os fenômenos físico-químicos associados com os movimentos da água em sólidos porosos são controlados pela permeabilidade do sólido. Para o estudo da permeabilidade do concreto com a adição de metacaulim foi realizado o ensaio de permeabilidade através de equipamento fabricado pela German Instruments e mostrado na Figura 4.

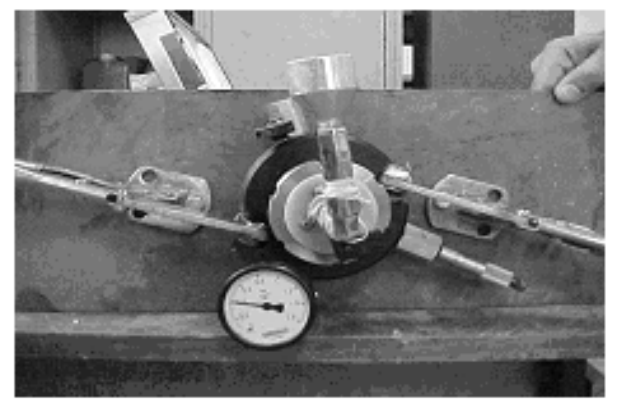

Figura 4. Ensaio de Permeabilidade (permeabilímetro)

O ensaio foi realizado a partir da escolha da pressão da água de 0,4 BAR que ira proporcionar a percolação de água para o interior de um provete de $10 \mathrm{~cm}$ de diâmetro e $3 \mathrm{~cm}$ de espessura, a partir de um tempo de observação de 30 minutos. O resultado fornece o fluxo de água sobre pressão passante pelo concreto expresso em $\mathrm{mm} / \mathrm{s}$. O resultado apresentado pela amostra de referência foi de $1 \times 10^{-8} \mathrm{~mm} / \mathrm{s}$ e nos concretos com adição de metacaulim foi de $1 \times 10^{-9} \mathrm{~mm} / \mathrm{s}$. Se se utilizar a Tabela 2 para efeito comparativo dos resultados (tabela de referência proposta pelos pesquisadores), conclui-se que os três concretos são de elevada impermeabilidade e consequentemente de alta durabilidade, sendo observada uma ligeira melhoria na impermeabilidade dos concretos quando da utilização do metacaulim.

Tabela 2. Padrões de referência para fluxos d'água sob pressão de 0,4 Bar passante por um concreto quando da utilização do permeabilímetro German

\begin{tabular}{|c|c|}
\hline Valores entre & Resultados \\
\hline 0 e $1,0 \times 10^{-3}$ & concreto de baixa impermeabilidade \\
$1,0 \times 10^{-3}$ e $1,0 \times 10^{-5}$ & concreto de média impermeabilidade \\
$1,0 \times 10^{-5}$ e $1,0 \times 10^{-6}$ & concreto de média/alta impermeabilidade \\
$1,0 \times 10^{-6}$ e $1,0 \times 10^{-7}$ & concreto de alta impermeabilidade \\
$1,0 \times 10^{-1}$ e $1,0 \times 10^{-y}$ & concreto de elevada impermeabilidade \\
\hline
\end{tabular}

Embora seja claro que o uso de metacaulim implica numa maior demanda por água de amassadura, os testes convencionais de trabalhabilidade, como o slump, não são capazes de quantificar com exatidão a influência dele na fluidez do concreto com metacaulim, principalmente quando se trata de concreto com baixas relações água/aglomerantes [3].

\footnotetext{
* Contribuição técnica ao $44^{\circ}$ Seminário de Redução de Minério de Ferro e Matérias-primas, 15ํ Simpósio Brasileiro de Minério de Ferro e $2^{\circ}$ Simpósio Brasileiro de Aglomeração de Minério de Ferro, 15 a 18 de setembro de 2014, Belo Horizonte, MG, Brasil.
} 


\section{CONCLUSÃO}

A utilização do metacaulim, produzido a partir da tecnologia DEMETER, na produção de concreto de alto desempenho, é viável e sinaliza para resultados bastante satisfatórios no que concerne a ganhos de resistência, melhoria da impermeabilidade e, por consequência, melhoria da durabilidade das estruturas. Entretanto, o presente trabalho foi realizado a partir de solo laterítico encontrado na região sudeste do Brasil, e para uma validação mais consistente dever-se-á amostrar em território Português, argilas passíveis de serem beneficiadas e calcinadas com foco na produção de metacaulim, e, posteriormente, avaliar o desempenho frente à metodologia de pesquisa apresentada neste artigo. A grande contribuição da tecnologia de produção da argila calcinada (metacaulim), utilizada neste trabalho (patente DEMETER/França), é que ela propõe um sistema onde as partículas durante o processo de queima ficam em suspensão e em constante movimentação, facilitando assim a queima do material com considerável redução no custo de produção. Os processos convencionais (fornos rotativos) dão uma inércia e uma falta de mobilidade muito grande às partículas dificultando sua queima e reduz a pozolanicidade do produto gerado. Este estudo é parte integrante de uma linha de pesquisa em desenvolvimento nos Departamentos de Engenharia de Materiais e Construção e de Engenharia de Minas da Escola de Engenharia da Universidade Federal de Minas Gerais, Brasil.

\section{Agradecimentos}

Agradecemos aos Departamentos de Engenharia de Materiais e Construção e de Engenharia de Minas pela parceria na publicação deste artigo e desenvolvimento do projeto.

\section{REFERÊNCIAS}

1 Mehta PK., Monteiro, P.J.M. Concreto - estrutura, propriedades e materiais. São Paulo: Ed. PINI, 1994.

2 Gama EM, Gomes AM, Gilbert R. Utilização de estéril argiloso para fabricação de metacaolin.IBRACON, 2006.

3 Helene $P$, Lacerda CS. Metacaulim uma nova opção para CONCRETO de alto desempenho. Instituto Brasileiro de Concreto. 44ํㅡㄹ Congresso Brasileiro de Concreto. Belo Horizonte, 2002.

4 Associação Brasileira de Normas Técnicas (ABNT), Rio de Janeiro. NBR 7214/86; Areia normal para ensaio de cimento - Especificação. Rio de Janeiro, 1990.

\section{BIBLIOGRAFIA}

$1 \quad$ NFP 98-232-3 - AFNOR- Association Francaise de Normalization, Paris, 1998.

$2 \quad$ NFP 98-230-2 - AFNOR- Association Francaise de Normalization, Paris, 1998.

3 NFP 98-200-2 - AFNOR- Association Francaise de Normalization, Paris, 1997.

\footnotetext{
* Contribuição técnica ao $44^{\circ}$ Seminário de Redução de Minério de Ferro e Matérias-primas, 15ํ Simpósio Brasileiro de Minério de Ferro e $2^{\circ}$ Simpósio Brasileiro de Aglomeração de Minério de Ferro, 15 a 18 de setembro de 2014, Belo Horizonte, MG, Brasil.
} 